\title{
Script of Healthcare Technology: Do Designs of Robotic Beds Exclude or Include Users?
}

Brodersen, Søsser Grith Kragh ; Hansen, Meiken; Lindegaard, Hanne

Published in:

Design Issues

Publication date:

2015

Document Version

Peer reviewed version

Link back to DTU Orbit

Citation (APA):

Brodersen, S. G. K., Hansen, M., \& Lindegaard, H. (2015). Script of Healthcare Technology: Do Designs of Robotic Beds Exclude or Include Users? Design Issues, 31(2), 16-28.

\section{General rights}

Copyright and moral rights for the publications made accessible in the public portal are retained by the authors and/or other copyright owners and it is a condition of accessing publications that users recognise and abide by the legal requirements associated with these rights.

- Users may download and print one copy of any publication from the public portal for the purpose of private study or research.

- You may not further distribute the material or use it for any profit-making activity or commercial gain

- You may freely distribute the URL identifying the publication in the public portal

If you believe that this document breaches copyright please contact us providing details, and we will remove access to the work immediately and investigate your claim. 


\title{
Script of Healthcare Technology: Do Designs of Robotic Beds Exclude or Include Users?
}

Søsser Brodersen, Meiken Hansen, Hanne Lindegaard

\begin{abstract}
The article discusses the design and implementation of robotic beds used for disability care in Denmark. It references the theoretical concept of script in design as developed by sociologist Madeline Akrich. The authors use Actor Network Theory (ANT) to examine the design challenges and socio-material context of the RotoCare and RotoFlex beds. Particular focus is given to the relationship between the beds and their users. It is suggested that while the design of the RotoCare bed excludes disabled users by requiring a caregiver to rotate the bed and allow them to get up, the design of the RotoFlex bed includes users by enabling them to change positions by pushing one button.
\end{abstract}

\section{Introduction}

Many new product designs are currently being implemented in the healthcare sector, and this development presents designers with challenges involving socially innovative design. In this article, we argue that designing assistive technologies requires that designers focus on multiple users and use practices. We see the design of assistive technologies as the design of socio-material assemblies [1], which includes an analysis of the products already used in relation to multiple users, their practices, and their wishes.

In this article we focus on the challenges in the implementation of two types of robotic beds used for disability care in a municipality in Denmark. We follow both the caregivers' and the disabled people's daily practices. Using Actor Network Theory (ANT), we explore the socio-material settings and the design challenges. The theoretical concept of "script"[2] is used to investigate how the artifacts (beds) and the multiple users go through a mutual adaptation process in their daily practice, and how this adaptation varies in different cases. The human/non-human actor perspective focuses on the relation between the designed artifact and the user in specific situations [3]. The analysis leads to a central question: How does the scripting of the beds affect the beds' use and the different users?

\section{Design for Safety}

For the past decade, design of healthcare technology has been a strategic arena in product development in Denmark. Danish foresight reports on robotics and aging conclude that integration of robot technology would help the functional ability of the elderly and disabled [4]. The reports reveal an important 
opportunity to create an age-integrated society where product innovation is based on: "[...] multidisciplinary interaction, the welfare model, and the Danish labor market model." 5 The robotics study concludes that robots have great potential for alleviating critical problems and promoting innovation in areas of importance to society [6]. The report identifies design areas as "...care for the elderly, personal care, assistance for people with physical disabilities, ... and a better physical working environment."

Many healthcare technologies are developed as a means to treat work-related diseases and to improve the physical working environment. In the healthcare sector, back-related injuries with resulting sick days account for a considerable cost to society. Statics from The National Board of Industrial Injuries in Denmark show that back injuries, in general, accounted for 17 percent of the total reported injuries in 2002 [7]. Furthermore, most back injuries occur in work areas that involve caring for (nursing) people [8].

Maintaining quality of life for the elderly is gaining more attention, with an emphasis on the capacity for older people to "influence their own lives."[9]. As a result, companies are increasingly attending to the design of healthcare technology. But what is healthcare technology? According to the Danish Centre for Assistive Technology, healthcare technology includes technology solutions that are used by citizens who are recipients or consumers of the specific healthcare benefits and that either compensate for or support a functional impairment (of the citizen). Healthcare technology also includes technological solutions that support and are primarily used by staff members who deliver or provide healthcare services."[10] Healthcare technology is then designed for both the impaired person and the caregiver.

In the design of healthcare technology for the public sector, success is measured in terms of economic gains-for example, in the technology's capacity to save time, cause fewer injuries, or allow the elderly to become more self-sufficient.

\section{Design of Healthcare Technologies}

Exploring the dense amount of writings related to the design of healthcare technologies reveals that two disciplinary standpoints dominate: Design Methodology Studies and Science and Technology Studies (STS). Design Methodology Studies originates from Bruce Archer's work on the "King's Fund Bed" in the 1960s [11]. Archer's argument was that the character of design problems made them too complex to be solved solely by designers; thus, he argued for approaching design in a logical and systematic manner, which, among other things, meant opening up the design process and allowing for the influence of information about user needs [12]. Designing the King's Fund Bed had a two-fold aim: (1) designing a hospital bed suitable for use by the majority of patients and providing proper work positions for healthcare workers, and (2) unravelling and generating new, systematic design methods. Scholars like Nigel Cross [13] and Elisabeth 
Sanders [14] have further elaborated on and modified these design methodologies, although not with a specific focus on healthcare design.

In STS studies, scholars have been interested in healthcare technologies and how these technologies affect the socio-material relations between the patients, disabled persons, and elderly persons; the healthcare workers; and work practices. One such researcher is Oudshoorn [15], who argues that "because human work is delegated to digital machines, face-to-face contacts between healthcare professionals, and ill patients, decrease because they are partly replaced by ICT-mediated clinical encounters." Oudshoorn argues that this development is problematic because it neglects what she calls the "invisible work," referring to the work involved in operating all the new technologies and devices. The tendency in both STS and healthcare studies seems to be to focus on nurses and specialists in telemedicine and their experiences and change of practice [16], and not so much to focus on the implications for the design of healthcare technologies. In previous work the authors of this article have taken initial steps to combine these two disciplinary points-STS studies and design methodology studies by discussing how assistive technologies designed for institutions change the everyday practices of disabled persons and their relatives when these technologies enter the private home. In our previous work and in this article, we discuss the dilemma and how it provides the opportunity to rethink how assistive technologies are shaped in their interplay with everyday life in private homes. We do so with an emphasis on embodiment, script, and domestication [17].

\section{Framework for an Ethnographic Study of Healthcare Technologies}

This article is based on a study conducted in collaboration with a Danish municipality. The study's purpose was to examine implementation of two robotic beds-RotoCare and RotoFlex. The municipality's leaders and politicians wanted to face the challenges of healthcare technology, so they conducted a workshop. The result was the purchase of four robotic nursing beds: three RotoCare and one RotoFlex. The "safety" team was responsible for initiating and testing the beds through a pilot-implementation phase; its main task was to optimize the working conditions of employees in the elderly care sector in the municipality. Team members decided to carry out a study in three different locations, with one RotoFlex bed and one RotoCare bed placed in a rehab center and two RotoCare beds placed in two different nursing homes. We were engaged in the project to study the use practices in relation to the beds.

The criteria for use practices were based on the need to determine whether the beds could serve the purpose of taking care of more people with fewer hands. To efficiently distribute the beds to the neediest users, we first had to identify a target group 
To address the study's dual interests-in economic issues (regarding both the citizens' health and the caregivers' occupational health) and the interest in quality of life for the citizens, we linked the former to the workload of the caregivers and sought to determine whether the beds had a positive effect on the nursing staff's workload. Reducing the workload was closely linked to the health of the caregivers because they are exposed to heavy lifting in awkward positions. The occupational aspects were also closely linked to the economic aspects because the reduction of the workload in some cases would mean freeing resources. Closely connected to challenges of healthcare technologies, there is an ongoing discussion in Denmark, that within a few years, the elderly part of the population will grow to an extent that the workforce for taking care of the elderlies, will be way too small. Thus, there is a need for freeing resources within the healthcare service sector. Still, the economic aspects were more centered on being able to do the job with fewer hands, and the occupational aspects were more centered on the caregivers' health.

Our engagement in the project resulted from our research interest in studying design scripts and the relations between human and non-humans actors. In the study, we focused on differences in the use practices of the two beds. We also studied the context in which the beds seemed to be most successfully used by all the users involved.

\section{Methodology}

Our study involved 18 informants: nine caregivers employed th the three nursing facilities and nine elderly citizens living in the nursing facilities. To gather a diverse sample of uses/practices, the beds were placed in three different caregiving facilities. In choosing where to place the beds in each facility, the (elderly) citizen's condition was crucial. To be included in the study, the (elderly) citizen had to have certain impairments, such as not being able to sit up in bed without help. Although the test group was quite small, we found great variation in the group. For example, citizen informants ranged in age from their 30 s to their 90s.

During the study, ethnographic observations were central in gathering material. Thirteen user observations were collected in nursing homes and rehab centers where impaired persons were aided in getting in or out of bed in their own apartments. The role of the researcher was a combination of "solely observer" and "observer-as-participant" [18]. In the literature, the one who only observes is removed from the setting of the informants and is unseen. The role of the observer-as-participant is described as observing subjects for a brief period of time and mean-while conducting structured interviews [19]. In this case, however, the observations occurred for brief periods of time but without informants could see the researcher, but only in the periphery while he or she observed specific daily chores. Afterward, the researcher carried out semistructured interviews in accordance with the caregiver's schedule. 
Ethnographic-inspired interview techniques were used to interview the 18 informants. The interviews entailed a combination of descriptive, structured, and contrasting questions to minimize the risk of imposing bias on the data, and the informants were mostly interviewed in "everyday life settings" [20]

To clarify whether the design was adequate for first-time users (here caregivers) to intuitively use the beds, we also conducted user tests with a person who had no prior experience in the care sector.

\section{The Concept of Script in Design and Use}

The script concept focuses on the fact that technologies are always inscribed in a framework. It describes the roles that the technological artifacts play in the heterogeneous networks in which they are situated, using a semiotic approach. As Akrich states, “...[L]ike a film script, technical objects define a framework of action, together with the actors and the space in which they are supposed to act" [21]. Thus, designers inscribe technological content into the new object, and the object's script is what users confronted when they interact with the physical object. The script can be described as a message from the designer to the user: It describes the product's intended use and meaning [22]. Although not a part of Akrich's notion of script, Hubak suggests a division of the script into a socio-technical one and a physical one [23]. Hubak argues that "...[t]he physical script is seeking to exercise direct influence over users, since it is promoting the product's physical properties and utilitarian function. The socio-technical script, on the other hand, is seeking to exercise influence by way of indirect attraction. This attraction can be more or less related to utilitarian, symbolic, and emotional arguments" [24].

According to Hubak, then, the definition of script includes both the physical and the socio-technical script: "I am arguing that technical objects participate in building heterogeneous networks that bring together actants of all types and sizes, whether human or non-human" [25]. In this description, actants clearly include marketing, advertising, and general media. To include both types of links between actants, she points out that the links that concern us are necessarily both technical and social.

In the area of healthcare technology, the analytical concept of script is seen in combination with other ANT concepts, including embodiment and domestication. For example, we have explored what happens when assistive technology enters private homes and the homes become hybrids of workspace and private space [26]. Focus in this article is on the implemented technology, and whether tight relations between the human actor and the non-human actor are built in. To analyze the implemented technology, concepts of domestication and script are used. In this investigation, the script becomes important because "... [i]t conceptualizes the connection of design and use. Some technologies are designed to assist the caregivers in their work (often in an institutional setting), while others are designed to assist the disabled people. This 
means that the designer has in-scripted not only the user but also the whole network, including work space, safety, longevity, etc., as representations" [27].

Law and Moser's research regarding a disabled woman focuses on the array of heterogeneous relations necessary for her to function [28]. In these stories, the non-human artifacts are described as being able to accomplish output together with the user by becoming an extension of the user. The stories show several examples of healthcare technologies that have evolved to give the disabled improved opportunities; one important example is the electric wheelchair. Little emphasis is placed on the importance of the nonhuman actors and their design to allow them to successfully become an extension of the user. For impaired people (e.g., the aged and handicapped), the scripting of the technology is important because they depend on technology for them to be "extended." Thus, exploring the script in relation to daily practices can provide insight into how the technology performs and its consequences for end-users. Exploring the scripts of technologies and their effect on end-users might inspire further development in the artifacts of healthcare technology to make them more suited to users' needs.

\section{Devices and Their Differences in Script}

In the study of the implementation of RotoCare and RotoFlex, we investigated the practices of getting in and out of bed. The question was: How does the scripting of the beds affect bed use and the end-users? Before the implementation of the new beds, the (elderly) citizens all used an average, hospital-type bed without the rotation function. We compared the practices of getting in and out of the bed before implementation and after.

In our study we used the script concept to explore the beds in relation to their settings and to all the human and non-human actors involved. Although the RotoCare and RotoFlex are quite similar in design, we found that their scripting is quite different. RotoCare has a weak script, while RotoFlex has a strong script. The analyses that follow focus on the consequences of the weak vs. strong scripts, and on how they affect the human actors.

The RotoFlex and RotoCare beds have certain similarities and differences. Their key function is that the upper part of the 

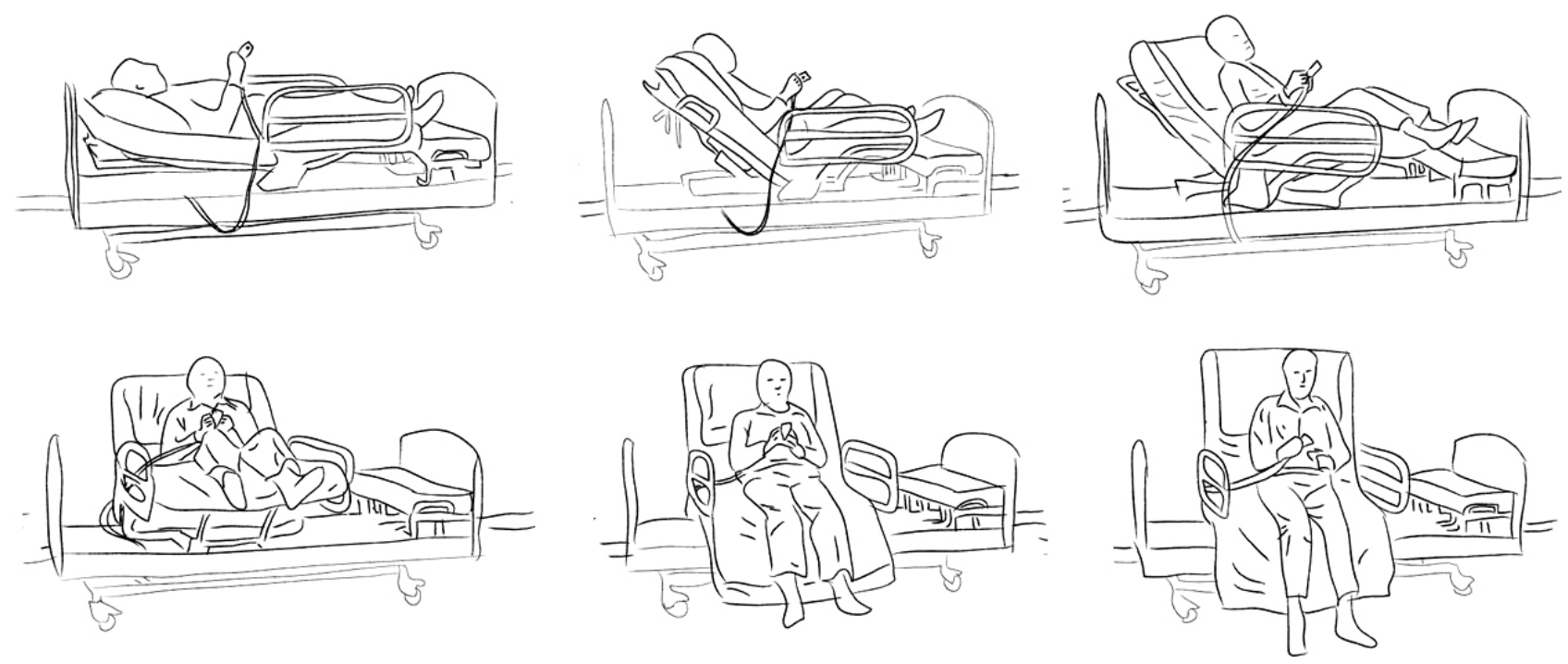

Figure 1. The rotation process of the RotoFlex bed.

bed can rotate to take the form of a chair. The rotation function is electronic in the RotoFlex bed, while it is manual in the RotoCare bed. The beds need to be placed roughly $40 \mathrm{~cm}$ from the wall when performing the rotation function.

In a RotoFlex bed, the whole process of changing from a prone position to a sitting one can be accomplished by pushing one button. When care receivers want to get up, they simply hold the remote and push a button until they are in a position from which they can stand (see Figure 1). The process is reversed to lie down: care receivers sit on the chair-shaped mattress and push the button until they are lying in the bed.

Because the rotation function of the RotoCare bed is manual, the care receiver has to depend on a second person to get up; thus, both caregiver and care receiver are "users." In the RotoCare procedure, users must decide which part of the bed to elevate first-the back part or the leg part. The decision is necessary to avoid damaging the bed, which results if the back and leg parts are not raised adequately before trying to rotate the mattress. Furthermore, users must consider how much both parts should be elevated so that the care receiver sits comfortably (see Figure 2). Thus, the bed allows actions that can harm both it and the care reciever. Although an instruction manual describing (scripting) the behavior required of users is delivered with the device, users can easily ignore or overlook this kind of manual. Other than the manual, nothing on the device indicates that users must be careful of the mattress and the person in the bed.

To allow care recievers to get up, the caregiver must turn a handle (lock) behind the upper part of the bed, which allows the upper part to rotate. Then, decisions must be made about how to rotate the bed and where to hold on to the guardrail during rotations. After rotation, the caregiver turns the handle back to ensure 

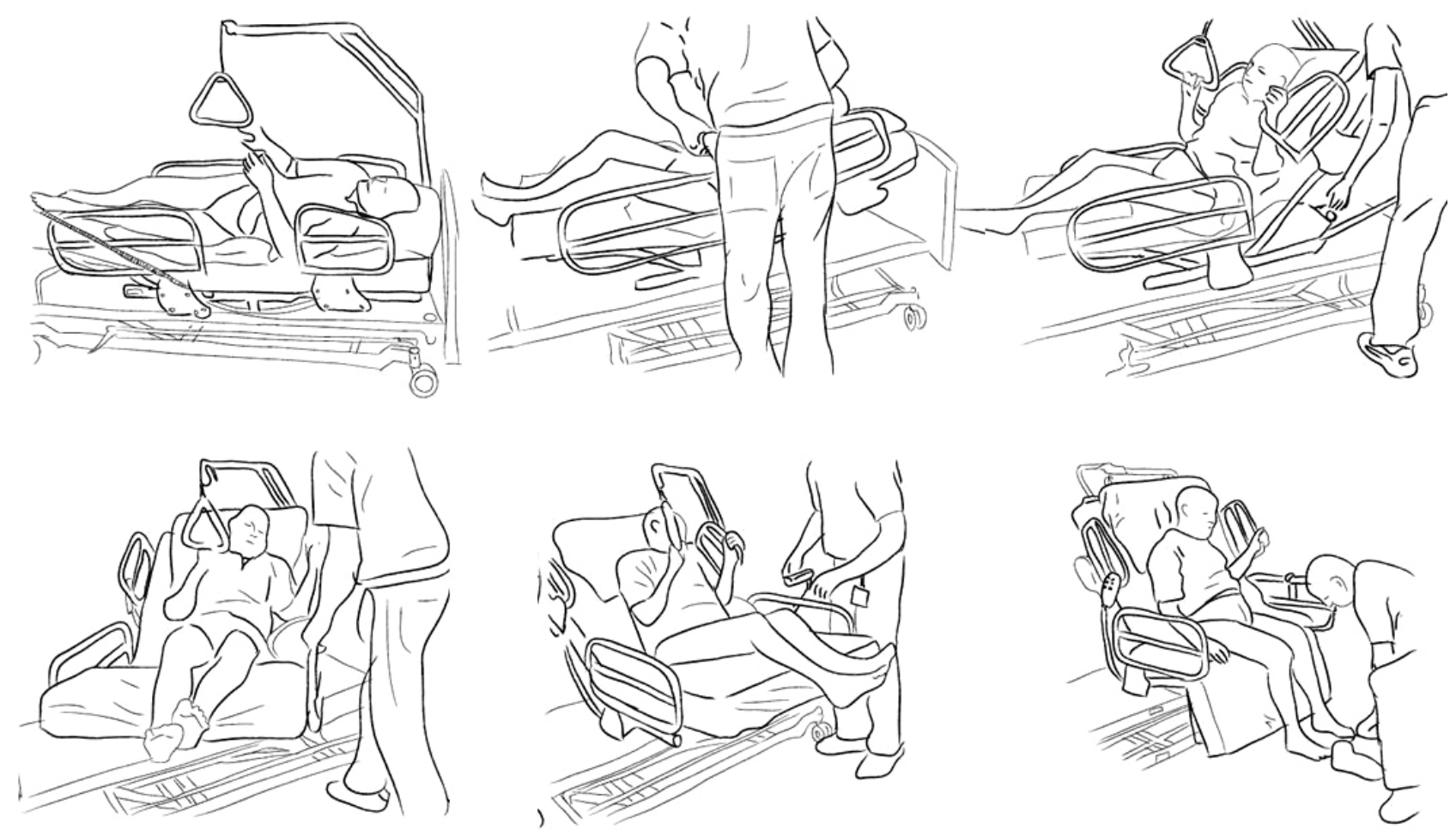

Figure 2. A usage situation with the RotoCare bed. The user is assisted out of bed.

that the upper part does not rotate involuntarily and possibly cause an accident. From here, users can push two buttons to form the bed into a chair, deciding first whether to lower the leg part or to raise the back part, and then whether the two adjustments together are appropriate to make the care receiver comfortable and keep him or her from sliding onto the floor. Again, neither the device nor the user manual describes (scripts) how the impaired user can achieve maximum comfort.

Aune offers the following understanding of scripts "A strong script suggests a certain kind of use, a weaker script suggests a larger degree of flexibility" [29]. In light of this definition, RotoFlex's strong script and RotoCare's weaker script can become clearly identified. When operating the RotoCare bed, users are allowed multiple actions. And because each impaired care receiver has multiple caregivers, the impaired person has to endure multiple ways of getting into bed. This variation may not be problematic, but some people feel insecure and uncomfortable with a new routine every night. People suffering from dementia surely will experience it as a problem. Another concern with allowing multiple actions relates to the caregiver. For substitutes, having to navigate among multiple choices because of the weak scripting can very well be a time-consuming affair. Time is of value in the care sector, and if substitutes are in a hurry and make mistakes, they could cause damage to the artifact and create anxiety in the care receiver. After the RotoCare beds had been used for a period of three months, several marks were found on the mattresses 
that could be attributed to wrongful use. In contrast to the RotoCare bed users, RotoFlex bed users have very limited options. Users press one of just two buttons: one for getting out of bed and one for getting into bed. Thus, use of the bed involves a minimum chance of wrongful operation.
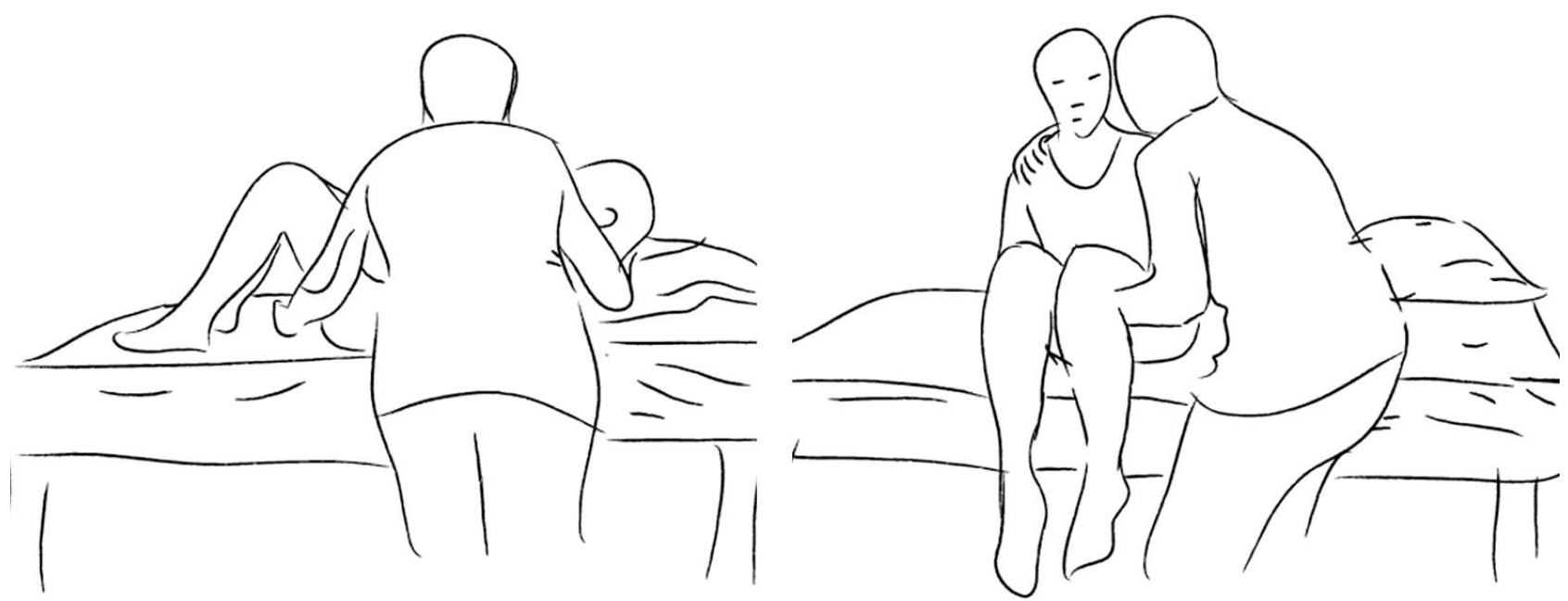

Figure 3. The rotation process Maria experienced when getting out of bed.

\section{Maria and the RotoFlex Bed}

When Maria was in her twenties, she was in a traffic accident that caused injuries to her nervous system and left her in a wheel-chair. In her thirties now, she enjoys sailing and is continuously educating herself to gain knowledge and keep busy. Since the traffic accident, she has required assistance getting out of bed. The public sector grants her help: She has an assistant who is present the whole day, and she has the opportunity to have assistance during the night, too. Because of hyper-mobile joints, Maria is easily injured when being helped in and out of bed manually. To prevent these injuries, several lift-technologies were tested, but without benefit; Maria kept getting injured. She expressed her frustration: "Most people need something good in their lives, not just to lie there and wait for the next joint to get sprained or shoulder to get dislocated...."

During the night Maria could not get out of bed by herself but had to call a caregiver, who was usually unknown, to help her. Because in Denmark using a lifting device requires more than one caregiver to be present, making such a call would mean that she would be lifted without the aid of any technology. Instead, Maria would have to lift her back so the caregiver could place one arm behind her back and one under her knees and then rotate her body 90 degrees (see Figure 3). This procedure was very painful, and so she tried to avoid calling for help. For example, to avoid the loss of sleep, she would try not to drink much fluid during the day, which was not ideal either. 
Maria actively searched for a solution. She found an advertisement for the RotoFlex bed in a magazine and was able to test it at a medico fair [30]. She discovered that she was able to get in and out of the bed without assistance, and she was granted the bed for a trial period of ten months by the bed's distributor. Maria reported the following:

My movement capability has improved considerably since I got the bed. In the beginning, I found it a bit difficult to move over, but I could use the lift and tie it around my waist in case I lost my balance or something else happened (...). Or if I did not feel confident because of a sprained shoulder, I used the lift as a safety device. The RotoFlex bed has changed my situation from continuously getting injured to getting better.

Maria had been used to getting out of or into bed either by a lift or by being lifted by a caregiver. In both cases, she was assisted by a caregiver, which limited the chance of an accident. With the RotoFlex bed, she was able to transfer herself on her own. The transfer was risky; if she fell, she could be seriously injured. Maria had to build up courage to be able to use the new device as prescribed. To get into the bed, she had to stand on her feet while supporting herself using the guardrail, then turn and sit on the bed. To do this, she needed to build up balance and strength. Furthermore, she also had to adjust her behavior and negotiate with her additional assistive tools. She discovered how she could use her stand-up lift as a safetydevice during the transfer: The stand-up lift could ease her fall if she lost her balance and give her a sense of security. She began making this new technology her own by adjusting to the apparatus both physically and physiologically.

With the capability of getting in and out of bed without assistance, Maria began drinking more fluids, which improved her general condition. She also began to feel better because her joints were no longer sprained. The RotoFlex bed thus has made a more normal life possible for Maria, despite her disability. She now sleeps on the RotoFlex bed, controls it, and she is "extended" by it.

Maria now considers herself to be a "normal" young woman and has a large network outside her "handicap network." In light of her normalcy, the RotoFlex bed looks out of place. Its script does not suit a young woman's home. The design of the bed, with steel rods and steel frame, resembles something found in caregiving facilities. Still, the bed has given Maria the experience of a private life. Its entry into her life has meant a new beginning: a life in which she is able to take control of the basic acts of getting in and out of bed. The caregiver and the RotoFlex bed can be seen as actors with multiple purposes-among them, the one similar purpose of helping Maria in and out of bed. This example of assistive technology thus goes beyond the caregiver's qualifications. One great quality is that it is not human and thus allows privacy. The symbolic meaning of the bed for Maria is entangled with its functions, giving her the possibility of a private life. 


\section{Søren and the RotoCare Bed}

Søren is in his mid-nineties and lives in a nursing home. He is not able to perform daily tasks without assistance, and he requires a lot of physical effort from the caregivers.
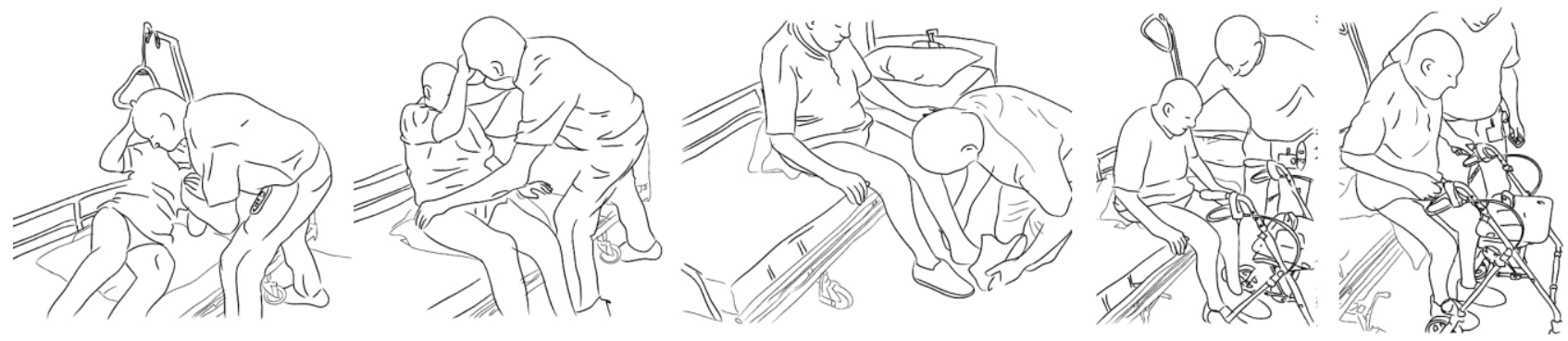

Figure 4. The process of getting out of bed before the arrival of the RotoCare bed.

Søren's process of getting out of bed with the hospital bed is quite demanding for his caregiver (see Figure 4). The first step of the process is to lower the bed to a height that allows Søren to put his feet on the floor when seated. The upper part of the bed is then lifted, and Søren grabs the triangle for support. The caregiver pulls Søren into a sitting position on the bed, puts on Søren's shoes while he sits with his feet on the floor, and positions the walker in front of him. Søren grabs the handles and stands up; the effort sometimes causes him to tremble.

The same process of getting out of bed after the arrival of the RotoCare bed is shown in Figure 2. Because the pulling movement is no longer necessary, the strain on the caregiver's back is removed. Instead, the caregiver now has to turn a handle, manually rotate the bed, and turn the handle again.

During the study, Søren became less able to stand up and was no longer able to walk with a walker. As a result, the caregivers needed to use a stand-up lift to move Søren from the bed and into the bathroom. Thus, the script of the bed seems intuitively to afford switching technology between the bed and outside the bed. For example, the process of going to the toilet is as follows: Søren moves from his wheelchair onto the toilet. From the toilet, he is placed in a stand-up lift and rolled toward the RotoCare bed (set in the chair position). Søren is then lowered on to the bed (see Figure 5), and the bed then is rotated to the lying position.

When asked of the process, Søren says, "...It is neither better nor worse than my previous hospital bed." The caregiver prefers the RotoCare bed to the traditional hospital bed. According to him, moving Søren from the stand-up lift to lying in the bed is more controlled. With the ordinary hospital bed, Søren's back has no support when the caregiver lowers Søren onto the bed. In this situation, the caregiver has to lift Søren's legs onto the bed one at a time. The caregiver says "I would experience dead weight more often, since he often becomes insecure and is not aware of what movements we are in the middle of...." 
The caregiver also points toward another problem: The movements that the caregivers need to perform to place the impaired person correctly in the bed are very demanding, and
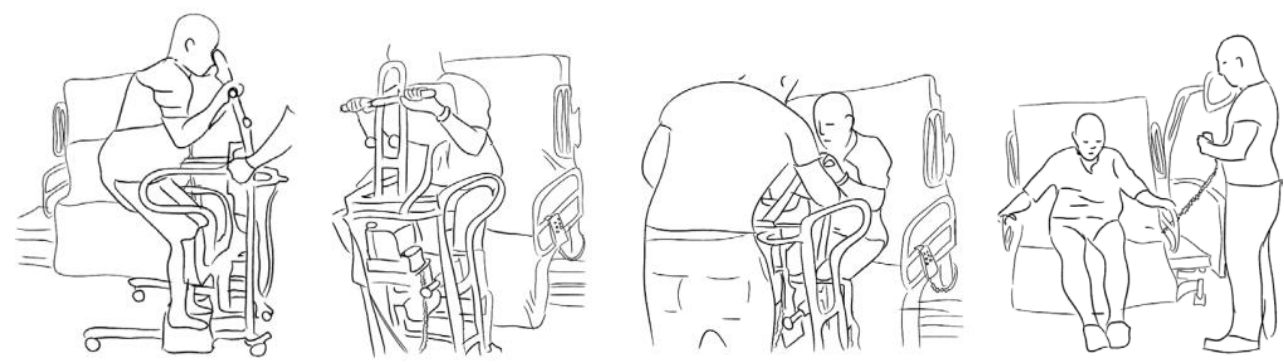

Figure 5 Søren and the caregiver is using a lift and a RotoCare bed.

the RotoCare bed does not solve this. Thus, the problems that the bed does solve are undermined by the problems that it does not solve. When discussing the bed and the effects on Søren, the caregiver suggests that "if Søren had a ceiling-lift in his room, he might not need the bed." This may suggest that the artifact is in the process of being phased out and replaced by a ceiling lift.

For both the RotoCare or RotoFlex beds, the instructions make clear that all users should be properly trained by professionals before using the beds. However, nursing homes in Denmark depend on hiring substitutes when regular staff members are absent. Furthermore, high turnover of personnel, especially among the weekend staff, is not unusual. These issues make it difficult to ensure that all personnel are always trained in the use of all the equipment. Thus, Søren's caregivers often were unaware of how to operate the RotoCare bed.

In contrast with Maria's situation, Søren has no feelings for the bed whatsoever; he has not "connected" with it. Thus, the ones most affected by this particular RotoCare bed are the caregivers, who use it as they use the lift for getting Søren into the bathroom. Although Søren sleeps in the bed, he is not able to control the main function of the bed: the rotation function.

Although a weak script might be a disadvantage for the care receiver, in some aspects it can be satisfying for the caregiver. A caregiver with experiences with both beds sees some of the prescriptions of the RotoCare bed as an advantage, compared to the RotoFlex bed's proscriptions. In using the RotoFlex, she discovered that she did not agree with the pre-programmed order of raising and lowering the back and leg parts of the RotoFlex bed. The caregiver noted "the RotoCare bed has some features where I am in charge. I would like to transfer those features to the RotoFlex bed." Because of the proscriptions, she could not operate the RotoFlex bed according to her preference. The rigid script can cause caregivers who have years 
of experience to feel a loss of power. The shift in the balance of power means that the caregiver loses power to the technology.

\section{Conclusion}

Through an ethnographic study and with theoretical inspiration in Akrich's concept of scripts, our study indicates some important considerations in designing healthcare technologies. We have explored the objects-the RotoCare and RotoFlex beds-in relation to their settings, as well as the assemblages of human and non-human actors. Although the two beds appear identical, the scripting of the beds is very different. The technologies of the beds, including the weak vs. strong script, have a central effect on both the care receivers and the caregivers. In Søren's case, the manual rotation function (non-human actor) excluded him from becoming a user. The weak script led to multiple test-trials, which can make life difficult for citizens in nursing homes.

Because of the technologies of the RotoFlex bed, the person in the bed more easily can be seen as a "user" of the bed's function, as we saw in the case of Maria. Here, RotoFlex enabled Maria to perform actions not possible before. She became independent. Although a RotoFlex bed does not necessarily allow all care receivers to get out of bed on their own, having the option and being completely excluded from the possibility makes a difference. For this reason-that it more likely meets the goal of improvement- we might argue that the RotoFlex bed is the better choice between the two.

\section{References}

[1] Bruno Latour, Pandora's Hope: Essays on the Reality of Science Studies (Cambridge, MA: Harvard University Press, 1999).

[2] Madeline Akrich, "The Description of Technical Objects," in Shaping Technology/Building Society: Studies in Sociotechnical Change, ed. Wiebe Bijker and John Law (Cambridge, MA: MIT Press, 1992). [3] Latour, Pandora's Hope, 176-274.

[4] "Ageing Society 2030: Report by the Steering Group for the Strategic Foresight on the Ageing Society 2030" (Copenhagen: Danish Council for Strategic Research. Ministry of Science, Technology and Innovation, 2006); "Technology Foresight on Cognition and Robotics" (Copenhagen: Danish Ministry of Science, Technology and Innovation, 2006).

[5] Danish Ministry of Science, "Ageing Society 2030."

[6] Danish Ministry of Science, "Technology Foresight." 
[7] "Arbejdsskadestatistik 2002," [Work Injury Statistics 2002] www.ask.dk/ / media/ASK/pdf/statistik/arbejdsskadestatistik2002pdf.ashx (accessed September 16, 2013).

[8] Nils Fallentin, Anne Faber and Muborak Sharipova, "Fysiske Belastninger i Plejearbejdet-Resultater fra en Spørgeskemaundersøgelse i den Kommunale ÆEldrepleje" [Physical Strain in Healthcare Work Results from a Questionary Survey in the Municipality Healthcare Service] (SOSU-rapport nr. 14. Copenhagen: Det Nationale Forskningscenter for Arbejdsmiljø, 2007).

[9] Kommission om Livskvalitet og Selvbestemmelse i Plejebolig og Plejehjem, "Livskvalitet og Selvbestemmelse på Plejehjem" [Quality of Life and Self-determination in Nursing Home] (Copenhagen: The Ministry of Social Affairs, Children and Integration, 2012).

[10] "Hjælpemiddel Instituttet" [Assistive Technology], www.hmi.dk/page1579.aspx (accessed August 10, 2012).

[11] Bruce Archer, "The Structure of the Design Process," in Design Methods in Architecture, ed. Geoffrey Broadbent and Anthony Ward (London: Lund Humphries, 1969), 76-102; Bruce Archer, Systematic Method for Designers (London: COID, 1965).

[12] Ghislaine Mary Lawrence, “Hospital Beds By Design: A Socio-Historical Account of the 'King's Fund Bed 1960-1975" (PhD diss., University of London, 2001).

[13] Nigel Cross, "The Recent History of Post-Industrial Design Methods," in Design and Industry, ed. N. Hamilton (London: Design Council, 1980); Nigel Cross, Developments in Design Methodology (Chichester: John Wiley, 1984).

[14] Elizabeth Sanders and Pieter Jan Stappers, "Co-Creations and the New Landscapes of Design," CoDesign 4, no. 1 (2008): 5-18.

[15] Nelly Oudshoorn, "Diagnosis at a Distance: The Invisible Work of Patients and Healthcare Professionals in Cardiac Telemonitoring Technology," Sociology of Health \& IIIness 30, no. 2 (2008): 272.

[16] Maggie Mort, Carl May, and Tracy Williams, "Remote Doctors and Absent Patients: Acting at a Distance in Telemedicine?" Science, Technology and Human Values 28, no. 2: 274-95; Nelly Oudshoorn, Margo Brouns, Ellen van Oost, "Diversity and Distributed Agency in the Design and Use of Medical VideoCommunication Technologies," in Inside the Politics of Technology, ed. Hans Harbers (Amsterdam: Amsterdam University Press, 2005); Gerard Hanlon et.al., "Knowledge, Technology and Nursing: The Case of NHS Direct," Human Relations 58, 2 (2005): 147-71.

[17] Søsser Brodersen and Hanne Lindegaard, "Ability or Disability - Design for Whom?" Scandinavian Journal of Disability Research (2013), dx.doi.org/ 10.1080/15017419.2013.803499 (accessed July 21, 2013). 
[18] Patricia A. Adler and Peter Adler, Observational Techniques: Handbook of Qualitative Research (Saga Publications, 1994).

[19] Adler et al., Observational Techniques

[20] James Spradley, The Ethnographic Interview (Orlando: Harcour Brace Jovanovich College Publishers, 1979).

[21] Madeline Akrich, "The Description of Technical Objects," 208.

[22] Kjetil Fallan, "De-scribing Design: Appropriating Script Analysis to Design History," Design Issues 24, no. 4 (Autumn 2008): 61-75.

[23] Marit Hubak, "The Car as a Cultural Statement," in Making Technology Our Own? Domesticating Technology into Everyday Life, ed. Merete Lie and Knut H. Sørensen (Oslo: Scandinavian University Press, 1996), 175.

[24] Ibid.

[25] Ibid.

[26] Hanne Lindegaard and Søsser Brodersen, "Homespace or Workspace? The Use of Multiple Assistive Technologies in Private Dwellings," in New Technologies and Emerging Spaces of Care, ed. Michael Schillmeier and Miquel Domènech (Farnham: Asgate, 2010): 95-107.

[27] Ibid., 6.

[28] John Law and Ingunn Moser, "Good Passages, Bad Passages," in Actor Network Theory and After, ed. John Law and John Hassard (Oxford: Sociological Review and Blackwell, 1999): 196-219.

[29] Magrethe Aune, "Users versus Utilities: The Domestication of an Energy Controlling Technology," in Technology Studies \& Sustainable Development, ed. Andrew Jamison and Harald Rohracher (Vienna: Profil Verlag, 2002): 390.

[30] The company Comfort Design is the sole distributor of RotoFlex and RotoCare in Scandinavia. 